\title{
Iatrogenic gallbladder perforation treated by laparoscopic cholecystectomy
}

\author{
S GRAHAM, S HERMANN, WT DEPEW MD FRCPC, RF PACE MD FRCSC
}

\begin{abstract}
S GRAHAM, S HERMANN, WT DEPEW, RF PACE. Iatrogenic gallbladder perforation treated by laparoscopic cholecystectomy. Can J Gastroenterol $1994 ; 8(1): 39-40$. A case of gallbladder perforation with bile peritonitis resulting from a percutaneous needle biopsy of the liver is presented. Using laparoscopic cholecystectomy as the surgical management, the patient made a rapid and smooth recovery.
\end{abstract}

Key Words: Bile peritonitis, Laparoscopy, Liver biopsy

\section{Perforation iatrogène de la vésicule biliaire traitée par cholécystectomie laparoscopique}

RÉSUMÉ : Un cas de perforation de la vésicule biliaire avec péritonite biliaire résultant d'une biopsie percutanée du foie à l'aiguille est présenté. Une cholécystectomie laparoscopique a été pratiquée chirurgicalement et le patient a rapidement guéri et récupéré.

\footnotetext{
L
} APAROSCOPIC CHOLECYSTECtomy is considered the elective treatment of choice for symptomatic cholelithiasis (1), but its use to manage acute biliary disorders, including gallbladder trauma, is less well defined. We present a case of iatrogenic gallbladder perforation that occurred during a percutaneous needle biopsy of the liver, which was managed by laparoscopic cholecystectomy. right upper abdominal pain and had evidence of guarding with rebound tenderness. The pain and rigidity rapidly spread to involve the entire abdomen, and a diagnosis of bile peritonitis due to gallbladder perforation was made.

The patient was stabilized and taken to the operating room where a laparoscopy was performed. Bile-stained fluid was seen throughout the upper abdomen. The gallbladder was partially hidden by hematoma and overlying omentum. After the gallbladder was mobilized, it was evident that the perforation was located in the region of Hartmann's pouch. A laparoscopic cholecystectomy was performed, but dissection was made difficult by the extensive hemorrhage within the tissues, which obscured the tissue planes. Following completion of the cholecystectomy, a generous lavage of the peritoneal cavity and the right upper abdominal quadrant was carried out, and a closed-suction drain was placed in Morrison's pouch. A laparoscopicguided percutaneous needle biopsy of the liver completed the operative procedure. The recovery was uncomplicated; the patient was discharged home on the third postoperative day and was at a full level of activity two weeks following surgery. 


\section{DISCUSSION}

Percutaneous needle biopsy of the liver routinely is used to diagnose a variety of hepatic disorders, and is associated with a procedure-related morbidity of $5.9 \%$ (2). Complications of interest to surgeons include major hemorrhage, hemobilia, intrahepatic hematoma and arteriovenous fistulas, bile peritonitis and hemothorax (3-5). Our case deals with perforation of the gallbladder, which has been reported to occur in $0.03 \%$ of liver biopsies $(6,7)$.

Laparoscopic cholecystectomy is accepted as the procedure of choice for symptomatic cholelithiasis (1). However, indications for the laparoscopic approach are not as clearly defined for the treatment of emergent gallbladder disease or gallbladder trauma (8). In the case presented, the perforation oc-

\section{REFERENCES}

1. Litwin DEM, Girotti MJ, Poulin EC, Mamazza J, Nagy AG. Laparoscopic cholecystectomy: Trans-Canada experience with 2201 cases. Can J Surg 1992;35:291-6.

2. Perrault J, McGill DB, Ott BJ, Taylor WF. Liver biopsy: Complications in 1000 inpatients and outpatients. Gastroenterology 1978;74:103-6.

3. McGill DB, Rakela J, Zinsmeister AR, Ott BJ. A 21 year experience with major hemorrhage after percutaneous liver biopsy. Gastroenterology 1990;99:1396-400. curred in a previously normal gallbladder, presumably containing uninfected bile. The chemical peritonitis resulting from sterile bile can produce a potentially fatal hypovolemic shock if treatment is delayed. Bile peritonitis resulting from perforation of an inflamed gallbladder and treated by open cholecystectomy has a mortality rate of 8.6 to $15 \%(9,10)$. Early definitive surgical management is clearly indicated whenever the diagnosis of bile peritonitis is made.

\section{CONCLUSIONS}

In the past, traumatic gallbladder perforation was treated definitively by open cholecystectomy. In the presented case, the patient had no history of gallbladder disease, and it was anticipated that the organ and adjacent tis-

4. Yeneri RJ, Gordon SC, Fink-Bennett D. Scintigraphic and culdoscopic diagnosis of bile peritonitis complicating liver biopsy. J Clin Gastroenterol 1989;11:571-3.

5. Verhille MS, Munoz SJ. Acute biliary-vascular fistula following needle aspiration of the liver. Gastroenterology 1991;101:1731-3.

6. Dennison KG, Khoury D, Heironimus JD. Gallbladder perforation during liver biopsy diagnosed using hepatobiliary scintigraphy. A case report. Clin Nuc Med 1990;15:95-6. sues would be free from inflammatory changes that would impair the laparoscopic dissection. Although technically difficult due to the bruising which obscured the tissue planes, laparoscopic cholecystectomy was safe and effective in this case. To the authors' knowledge, this is the first reported case of a laparoscopic cholecystectomy for traumatic rupture of the gallbladder secondary to liver needle biopsy. The advantages of the laparoscopic technique for cholecystectomy in the emergent situation were demonstrated by the short, uncomplicated postoperative stay of only three days in the face of bile peritonitis due to a perforated gallbladder. Laparoscopic cholecystectomy should receive favourable consideration as management for gallbladder perforation in similar clinical circumstances.

7. Lindner H. Das risiko der perkutanen leberbiopsie. Med Klin 1971;66:924.

8. Hugh TB, Chen FC, Li B. Empyema of the gallbladder treated by laparoscopic cholecystectomy. Med J Aust 1991;154:417-8.

9. Ranson JHC. Perforation of the gallbladder. In: Way LW, Pellegrini $\mathrm{CA}$, eds. Surgery of the Gallbladder and Bile Ducts. Philadelphia: WB Saunders, 1987:265-73.

10. Felice PR, Trowbridge EP, Ferrara JJ. Evolving changes in the pathogenesis and treatment of the perforated gallbladder: A combined hospital study. Am J Surg 1985;149:466-73. 


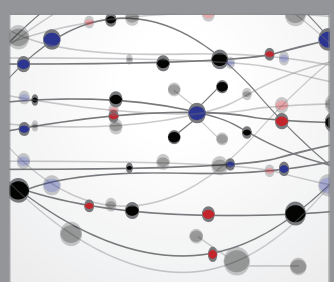

The Scientific World Journal
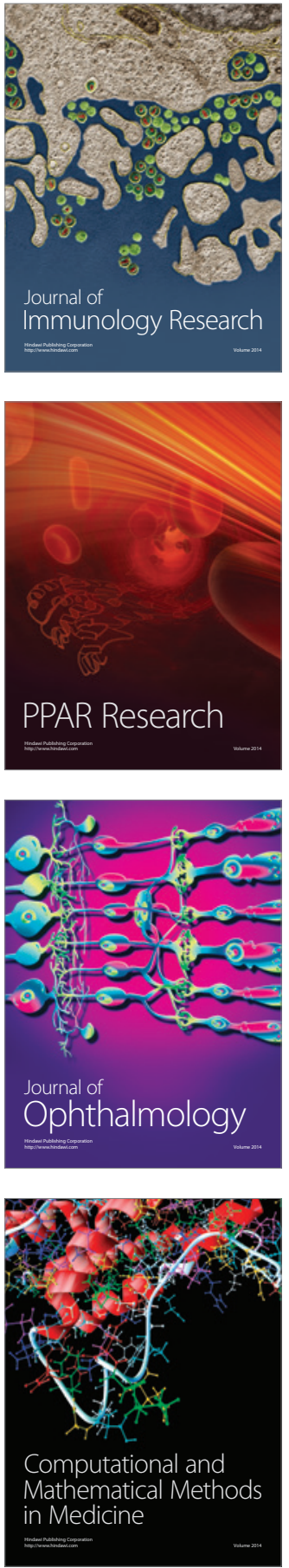

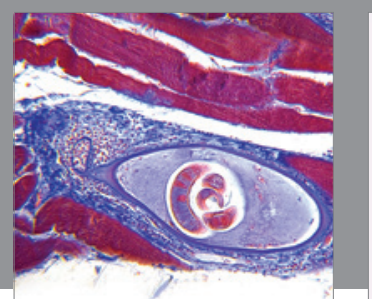

Gastroenterology Research and Practice

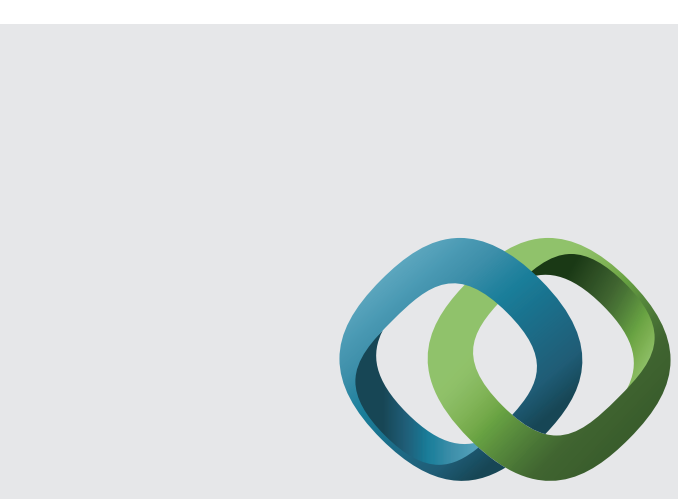

\section{Hindawi}

Submit your manuscripts at

http://www.hindawi.com
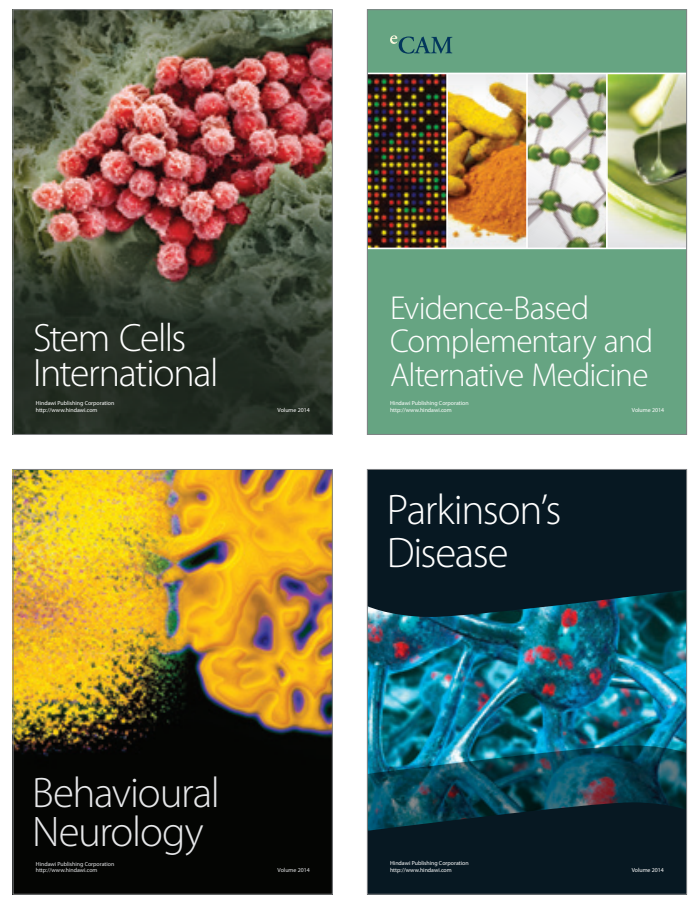
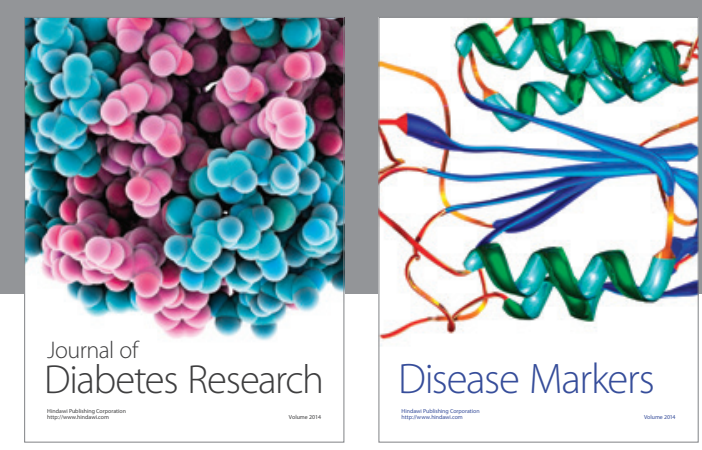

Disease Markers
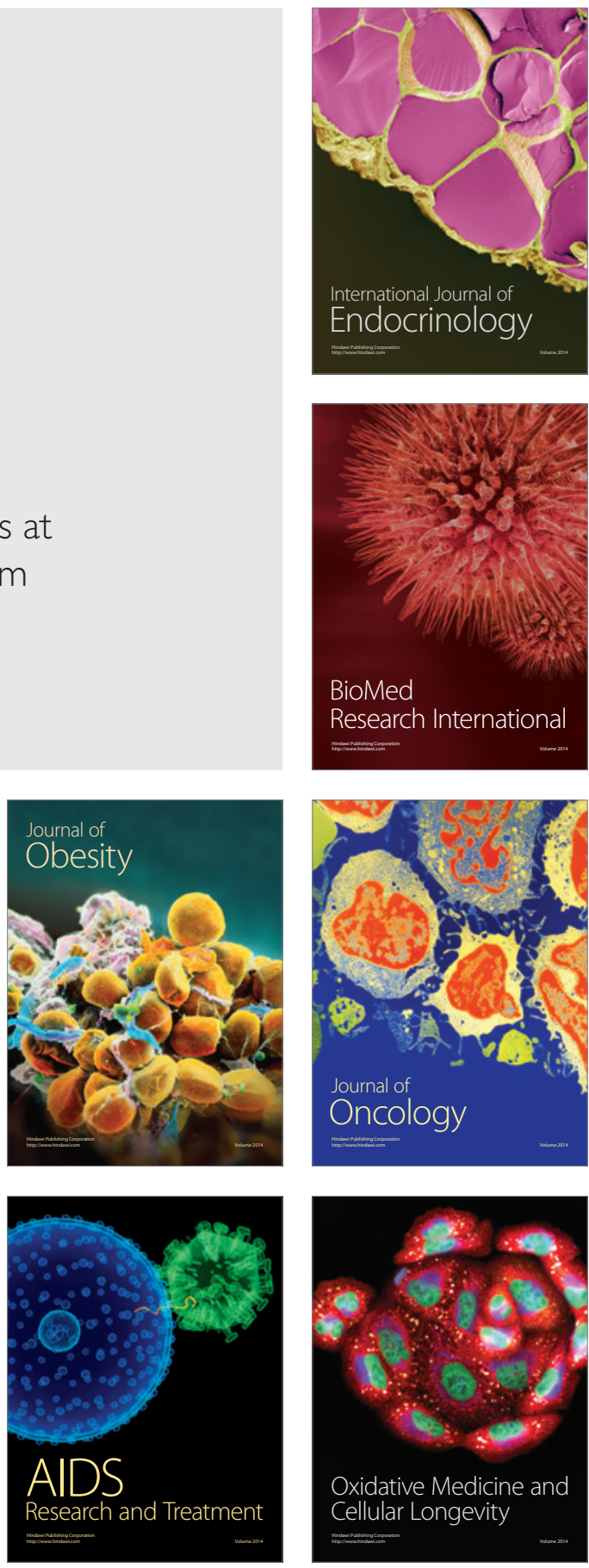